\title{
Nitrogen-Doped Carbon Spheres-Decorated Graphite Felt as a High-Performance Electrode for Fe Based Redox Flow Batteries
}

\author{
Anarghya Dinesh \\ Jyothy Institute of Technology \\ Anantha Mylarapattana Shankaranarayana \\ Jyothy Institute of Technology
}

Santosh Mysore Sridhar

Jyothy Institute of Technology

Narendra Kumar Muniswamy

Jyothy Institute of Technology

Krishna Venkatesh

Jyothy Institute of Technology

H B Muraralidhara ( $\square$ muralidhara.hb@ciirc.jyothyit.ac.in )

Centre for Incubation Innovation Research and Consultancy https://orcid.org/0000-0003-0184-9762

Original Research

Keywords: Iron redox flow battery, Nitrogen-doped carbon catalyst, Graphite felt, Electrode modification, Glycine, Efficiency

Posted Date: February 11th, 2021

DOl: https://doi.org/10.21203/rs.3.rs-177033/v1

License: (c) (i) This work is licensed under a Creative Commons Attribution 4.0 International License. Read Full License 


\section{Nitrogen-doped carbon spheres-decorated graphite felt as a high-performance electrode for Fe based redox flow batteries}

Anarghya Dinesh ${ }^{1,2}$, Mylarapattana Shankaranarayana Anantha ${ }^{1,2}$, Mysore Sridhar Santosh ${ }^{1}$, Muniswamy Narendra Kumar ${ }^{1}$, Krishna Venkatesh ${ }^{1}$, Handanahalli Basavarajaiah Muralidhara $^{1 *}$

${ }^{1}$ Centre for Incubation, Innovation, Research and Consultancy (CIIRC), Jyothy Institute of Technology, Tataguni, Off Kanakapura Main Road, Bangalore 560082, India.

${ }^{2}$ Visvesvaraya Technological University, Research Resource Centre, Jnana Sangama, Machhe, Belagavi 590018, India.

* Corresponding author

E-mail: hb.murali@gmail.com (H.B. Muralidhara)

Tel: +919739315239 


\begin{abstract}
In this paper, the performance of Fe based redox flow batteries (IRFBs) was dramatically improved by coating N-doped carbon spheres (NDCS) on the graphite felt electrodes. NDCS was synthesized by the single-step hydrothermal method using dextrose and ammonia as a precursor and coated over a graphite felt electrode by electrostatic spraying. The weight of NDCS required for the modification of the electrode to achieve the effective performance of the battery was studied using electrochemical techniques. Cyclic voltammetry (CV) and potentiodynamic polarization study was used to evaluate the kinetic reversibility and linear polarization resistance offered by the electrode towards electrolyte. The characterizing features of the NDCS, untreated graphite felt (UGF) electrode, and optimized modified graphite felt (MGF) electrode were analyzed using SEM, EDAX, XRD, and Raman spectroscopy. The charge-discharge studies were performed for the $132 \mathrm{~cm}^{2}$ IRFB using a $2 \mathrm{mg} / \mathrm{cm}^{2}$ MGF electrode as a positive electrode by varying the current densities from 20 to $60 \mathrm{~mA} / \mathrm{cm}^{2}$. The cell resulted in an average coulombic efficiency $(C E)$ of $93 \%$, voltaic efficiency $(V E)$ of $72 \%$, and energy efficiency $(E E)$ of $68 \%$ for 15 cycles at the current density of $30 \mathrm{~mA} / \mathrm{cm}^{2}$. The improvement in the performance of the IRFB is due to the presence of electrochemically active nitrogen-bearing carbon catalysts. In this paper, the pioneering effort has been made to improve the efficiency of the IRFB with an active area of $132 \mathrm{~cm}^{2}$ using glycine as the ligand.
\end{abstract}

Keywords Iron redox flow battery, Nitrogen-doped carbon catalyst, Graphite felt, Electrode modification, Glycine, Efficiency 


\section{Introduction}

Storage of energy harvested from renewable sources of energy such as wind, solar, hydro, etc is of major interest in the current scenario [1,2]. In recent days redox flow batteries are emerging as the sustainable technology to store the energy developed or harvested from renewable sources of energy [1-6]. Redox flow batteries are the one, which stores energy developed in the liquid electrolytes, thus they are power and capacity decoupled [3, 4, 7-11]. The various kinds of redox flow batteries comprising aqueous, non-aqueous, organic, or inorganic electrolyte systems that are gaining attention because of their high efficiency and lifecycles. Iron redox flow batteries (IRFBs) are the unique type of flow batteries that use the earth-abundant, economical, and environmentally friendly iron as the source of the reaction $[12,13]$.

IRFBs (Fig.1) is the one that stores chemical energy and reversibly converts it into electrical energy. The $\mathrm{Fe}^{3+} / \mathrm{Fe}^{2+}$, chloride electrolyte is used as a positive electrolyte and $\mathrm{Fe}^{2+} / \mathrm{Fe}^{0}$ electrolyte as a negative electrolyte $[14,15]$. The redox reactions occurring in the IRFBs are shown in Eqs. (1)-(3).

$$
\begin{array}{lll}
\text { Positive/Redox electrode: } & 2 F e^{2+} \leftrightarrow 2 F e^{3+}+2 e^{-} & E^{0}=0.77 \text { V vs. NHE } \\
\text { Negative/Plating electrode: } F e^{2+}+2 e^{-} \leftrightarrow F e^{0} & E^{0}=-0.44 \text { V vs. NHE } \\
\text { Overall: } & 3 F e^{2+} \leftrightarrow F e^{0}+2 F e^{3+} & E^{0}=1.21 \text { V vs. NHE }
\end{array}
$$

The ammonium chloride added to the electrolyte acts as the supporting electrolyte which shifts the plating potential of the electrolyte more negative. It has been mentioned in the literature that complexing the $\mathrm{Fe}^{3+}$ ions with ligands increases the stability of the anolyte and prevents precipitation $\mathrm{Fe}^{2+}$ as $\mathrm{Fe}(\mathrm{OH})_{3}[16]$. According to the literature, glycine exhibits a positively charged state, negatively charged state as well as zwitterion state. Addition of glycine to the iron-electrolyte forms a bond to iron ions in its negatively charged form and restricts the precipitation of $\mathrm{Fe}^{2+}$ as $\mathrm{Fe}(\mathrm{OH})_{3}[16]$.

According to the literature, carbon-based electrodes are the majorly used in the field of redox flow batteries because of their low cost, high stability, corrosion resistance, and high conductivity. But, these are poor in kinetic reversibility and electrochemical activity $[17,18]$. Hence it is essential to modify with electrochemically active substances such as metal-oxides, 
activated carbons, carbon nanotubes, graphene oxide or metal-carbon composites, etc. to increase the electrochemically active sites on the electrode surface $[18,19]$.

Studies reported in the field of energy storage consider carbon spheres as a promising material/catalyst because of their high surface area, chemical stability, and cost-effectiveness [20-23]. It has explained in the literature that, $\mathrm{N}$-doped carbon materials facilitate the formation of defects sites on the electrode surface which helps in the electrolyte absorption and hence increases the wettability of the electrode [17, 18, 24-26]. Also, these are described to exhibit greater electrocatalytic property in many electrochemical devices. Various reports explain the hydrothermal synthesis of carbon spheres from glucose precursors [27-30]. However very few reports available on the single-step hydrothermal synthesis of nitrogendoped carbon spheres using dextrose and ammonia as the precursors [20, 21].

The recent studies carried out for the electrode modification in IRFB using nitrogen-doped carbon particles and metal oxide composite reported good cycle life and kinetic reversibility towards $\mathrm{Fe}^{3+} / \mathrm{Fe}^{2+}$ reaction using ascorbic acid and glycine as the ligand respectively [18, 19]. The cell employed nitrogen-doped carbon particles resulted in a voltaic efficiency of $53.3 \%$ and with the maximum current uptake of $50 \mathrm{~mA} / \mathrm{cm}^{2}$. In these studies, the major focus has been given for the enhancement of coulombic efficiency $(C E)$ and cycle stability using a known electrolyte system. Yet there is a gap in the literature that leads to modification of electrode to enhance the overall efficiency of the IRFB which intern enhances the voltaic efficiency $(V E)$ and energy efficiency $(E E)$. To achieve higher voltaic efficiency of the battery, it is necessary to modify the electrode using an effective electrocatalyst which increases the electrocatalytic activity of the electrode by reducing ohmic resistance [31].

In this paper, N-doped carbon spheres (NDCS) synthesized hydrothermally using dextrose and ammonia as precursors were demonstrated as an effective electrocatalyst for the enhancement of the voltaic efficiency of IRFB. The optimization of the weight of NDCS required to get maximum kinetic reversibility of the reaction and low resistance was carried out using electrochemical measurements viz cyclic voltammetry $(\mathrm{CV})$ and potentiodynamic polarization studies. Charge-discharge studies were performed to measure $C E, V E$, and $E E$ of single-cell IRFB with an area of $132 \mathrm{~cm}^{2}$. The enhancement in the results of $C E, V E$, and $E E$ confirms that the modification of electrode using the NDCS as a catalyst plays a dynamic role in the performance of the IRFBs. According to the literature, there are no reports available on the modification of electrode for IRFBs with a larger active area of the cel $1[13,15,32,33]$. 
This is novel and potential work in the field of IRFBs to propose an effective catalyst for the modification of a positive electrode to increase the battery efficiencies.

\section{Experimental details}

\section{Materials}

All chemicals used in the experiments were procured from Sigma Aldrich, Bangalore. The graphite felt electrode was purchased from Rayon Graphite felt (AGFHT), USA, and the anion exchange membrane used in the cell was obtained from Fuel Cell Store, USA. The battery components such as glass-reinforced epoxy end plates (thickness $15 \mathrm{~mm}$ ), copper plates, and Teflon gaskets were fabricated in-house with flow patterns for different types of flow fields being machined with the help of a local vendor M/s Mersen India Pvt. Ltd., Bangalore.

\section{Synthesis}

NDCS were synthesized by the hydrothermal carbonization process using dextrose as the precursor. $10 \mathrm{~g}$ of dextrose was taken in $40 \mathrm{~mL}$ of water and $10 \%$ of ammonia solution was added to the mixture. The solution was stirred at $80^{\circ} \mathrm{C}$ for about 15 minutes and transferred to $50 \mathrm{~mL}$ Teflon-lined autoclave and treated at $180^{\circ} \mathrm{C}$ for 12 hours. The Autoclaved samples were allowed to cool till room temperature. The resultant black precipitate of NDCS was filtered, washed with water until the neutral $\mathrm{pH}$, and dried at $100^{\circ} \mathrm{C}[30]$.

\section{Positive electrode preparation}

The graphite felt electrode used in the study was sonicated using distilled water for 30 minutes to remove the loosely bound particles and dried in a hot air oven at $100^{\circ} \mathrm{C}$ overnight. The spray method was used for the modification of graphite felt using ethanol as a solvent. NDCS were well dispersed in ethanol by continuous stirring for about 24 hours. Nafion solution ( $5 \mathrm{wt} \%$ ) was added as a binder to the above solution and sonicated for five minutes. The prepared solution was sprayed over the electrode with the help of the Aimex H.V.L.P Traditional spray gun (H-827) attached to Zeal air compressor (Z 150) at a pressure of 4 bars. The solution of the desired weight concentration of NDCS was taken in the sprayer and coated on the previously weighed untreated graphite felt (UGF) electrode. The coated graphite felt electrodes were dried in the vacuum oven at $100^{\circ} \mathrm{C}$ overnight at a pressure of 25 PSI. The weight of the coated electrode was noted to validate the effective coating of the 
catalyst on the electrode surface. Repeated the process until the desired weight of the NDCS coated on the surface of the electrode. The weight of the NDCS coated over the surface of the electrode was varied from $1 \mathrm{mg} / \mathrm{cm}^{2}$ to $3 \mathrm{mg} / \mathrm{cm}^{2}$. The effective loading was confirmed by noting the weight of the graphite felt electrode before and after coating. The modified graphite felt (MGF) electrode was used as a positive electrode in the charge-discharge analysis of the battery.

\section{Negative electrode preparation}

The graphite felt electrode was thermally treated at $400^{\circ} \mathrm{C}$ for 30 hours and cooled to room temperature. The thermally treated graphite felt (TTGF) electrode was used as a negative electrode for performance studies of the battery [34].

\section{Electrochemical measurements}

The electrochemical activity of the MGF electrodes decorated with different amounts of NDCS was evaluated using $\mathrm{CV}$ and potentiodynamic polarization studies to optimize the suitable electrode for the battery performance using the Electrochemical analyzer (CH608E). The Electrochemical measurements were carried out using a three-electrode cell as shown in Fig. 2. The solution of composition $3.25 \mathrm{M}$ ferrous chloride tetrahydrate, $1 \mathrm{M}$ ammonium chloride, and $0.3 \mathrm{M}$ glycine was considered as the electrolyte. The $\mathrm{Ag} / \mathrm{AgCl} / 1 \mathrm{~N} \mathrm{KCl}$ was used as a reference electrode and Pt wire of $0.3 \mathrm{~mm}$ thickness was used as an auxiliary electrode. The MGF electrodes with a corresponding weight of NDCS were used as the working electrode. The CV studies were carried out at different scan rates varied from C10$100 \mathrm{mV} / \mathrm{s}$ with a potential window of -0.8 to $0 \mathrm{~V}$. The oxidation $\left(I_{\mathrm{pa}}\right)$ and reduction $\left(I_{\mathrm{pc}}\right)$ peak currents, the ration of $I_{\mathrm{p} a} / I_{\mathrm{pc}}$, and the difference of peak potential values $\Delta E$ were measured to study the reversibility of the reaction.

The potentiodynamic polarization study was carried out against the open circuit potential. The results of the electrochemical measurements of the MGF electrodes with different weights of NDCS coated over the electrode surface were compared to each other to optimize the desired weight of NDCS to be coated over the electrode surface.

\section{Electrodes characterization}

The crystallography of the NDCS, UGF, and MGF electrodes was characterized by X-ray diffractometry (XRD) on a BRUKER eco-D8 ADVANCE system working with $\mathrm{Cu}-\mathrm{K} \alpha$ 
radiation $(\lambda=1.54 \AA)$. The surface morphology and of TTGF and MGF electrodes were analyzed using scanning electron microscopy (SEM, HITACHI, SU3500) coupled to an energy dispersive analysis X-ray (EDAX) at an accelerating voltage of $10 \mathrm{kV}$. Raman spectra of electrodes were analyzed using (Horiba Jobin Yvon LabRAM) with $532 \mathrm{~nm}$ LASER at an exposure time of 5 seconds. The charge-coupled device (CCD) was used as a detector for the analysis with 1800 lines/mm grating.

\section{Performance characterization using $132 \mathrm{~cm}^{2}$ IRFB}

The charge-discharge studies of the battery $\left(132 \mathrm{~cm}^{2}\right)$ were studied using the Bitrode battery tester (LSV 1-100/0.1-47). The cell was constructed with glass-reinforced epoxy endplates, copper plates, serpentine flow configured graphite bipolar plates, and Viton gaskets. The in-flow pattern was configured for the movement of electrolyte inside the cell assembly. MGF electrode was used as a positive electrode whereas the TTGF electrode as the negative electrode. The commercially available anion exchange membrane was placed between the electrodes. $100 \mathrm{~mL}$ of the electrolyte solution was taken on either side of the battery and allowed to pass through the cell with a velocity of $120 \mathrm{~mL} / \mathrm{min}$. Charge-discharge studies were carried out by considering 1.5 and $0.8 \mathrm{~V}$ as charging and discharging voltage limits respectively. Studies were carried out by varying the current density from $20 \mathrm{~mA} / \mathrm{cm}^{2}$ to $50 \mathrm{~mA} / \mathrm{cm}^{2}$. The performance of the battery was calculated in terms of efficiencies using Eqs. (4) - (6). The result obtained is compared with the UGF electrode.

$$
\begin{aligned}
& \text { Coulombic efficiency }(C E)=\frac{\text { Discharge cuurent } \times \text { Discharge TIme }}{\text { Charge cuurent } \times \text { Charge TIme }} \times 100 \\
& \text { Voltaic efficiency }(V E)=\frac{\text { Average discharge voltage }}{\text { Average charge voltage }} \times 100 \\
& \text { Energy efficiency }(E E)=\frac{C E \times V E}{100}
\end{aligned}
$$

\section{Result and Discussion}

\section{Electrochemical measurements}

From Fig. 3A, it is noticeable that the electrochemical activity of the reaction increased significantly over the graphite felt electrode as a consequence of modification with NDCS. The oxidation and reduction peak current of the MGF electrode decorated with different weights of NDCS is given in Table 1 (The values are derived from the Electrochemical 
analyzer (CH608E)). The results indicate the shift in the oxidation peak potential of $2 \mathrm{mg} / \mathrm{cm}^{2}$ MGF electrode towards a negative direction as shown in the figure.

The ratio of anodic and cathodic peak current $\left(I_{\mathrm{p}} / I_{\mathrm{pc}}\right)$ will describe the reversibility of the reaction. The ratio obtained for $2 \mathrm{mg} / \mathrm{cm}^{2} \mathrm{MGF}$ electrode is closer to 1 than that of the other electrodes. Based on these results, it can be concluded that $2 \mathrm{mg} / \mathrm{cm}^{2}$ MGF electrode possesses greater electrocatalytic activity of $\mathrm{Fe}^{3+} / \mathrm{Fe}^{2+}$ reaction and hence is favorable for improving the energy storage of IRFBs. From Fig. 3B it is also evident that the peak potentials for the $\mathrm{Fe}^{3+} / \mathrm{Fe}^{2+}$ redox reaction on $2 \mathrm{mg} / \mathrm{cm}^{2} \mathrm{MGF}$ electrode is unchanged with increasing the potential scanning rate suggests that the concerned redox reaction is reversible on $2 \mathrm{mg} / \mathrm{cm}^{2}$ MGF electrode [35].

The potentiodynamic polarization study revealed that $2 \mathrm{mg} / \mathrm{cm}^{2}$ MGF electrode comprises fewer resistance values compared to other MGF electrodes. The Tafel plots obtained from the analysis has given in Fig. 4. The linear polarization value (derived using software) for 2 $\mathrm{mg} / \mathrm{cm}^{2}$ MGF electrode was found to be $2 \Omega$, which was least when compared to UGF (431 $\Omega), 1 \mathrm{mg} / \mathrm{cm}^{2}$ MGF electrode $(64 \Omega)$ and $3 \mathrm{mg} / \mathrm{cm}^{2}$ MGF electrode $(8 \Omega)$. The result obtained is well in agreement with the results of the CV. Thus, from the results of electrochemical measurements, the $2 \mathrm{mg} / \mathrm{cm}^{2}$ MGF electrode has been chosen as the positive electrode in the battery for further studies.

\section{Morphological characterization of electrodes}

The SEM images of the NDCS, UGF, and MGF electrodes are given in Fig. 5. The synthesized NDCS is in 3D - spherical shape with an average size of $5.80 \mu \mathrm{m}$ as shown in Fig. 5A. The UGF (Fig. 5B), TTGF (Fig. 5C) and MGF (Fig. 5D, 5E, and 5F) electrodes are having a 3D cross-link fiber-like structure. Impurities were seen on the surface of the UGF electrode which disappeared after the thermal treatment. The surface of TTGF was observed to be smooth and flat and fiber size seems to reduce as a result of which a larger active surface area is obtained as shown in Fig. 5C. The modified electrodes with the varied weight of NDCS deposited are presented in Fig. 5D, 5E and $5 \mathrm{~F}\left(1 \mathrm{mg} / \mathrm{cm}^{2}, 2\right.$ $\mathrm{mg} / \mathrm{cm}^{2}$, and $3 \mathrm{mg} / \mathrm{cm}^{2}$ respectively). The deposition of the carbon spheres over the electrode surface has increased with the increase in the weight of NDCS.

The results obtained from EDAX spectroscopy confirmed the presence of the nitrogen group in the synthesized NDCS. The result obtained from the analysis has shown in Fig. 6. 
The EDAX spectrum of the $2 \mathrm{mg} / \mathrm{cm}^{2}$ MGF electrode resulted in $8.55 \%$ of nitrogen and $9.05 \%$ of oxygen and $85.40 \%$ carbon. The presence of oxygen in the MGF electrode, as well as NDCS, can be resulted from the hydrothermal treatment. The rise in the percentage of carbon in the MGF electrode is well understood that the electrode is made up of graphite based material which is an allotropic form of carbon.

The diffractogram recorded for the NDCS, UGF, and MGF electrodes is given in Fig. 7. The increase in the intensity of the (002) offset of $2 \mathrm{mg} / \mathrm{cm}^{2}$ MGF electrode can be attributed to the decorated NDCS. The (100) and (110) offsets in the UGF and $2 \mathrm{mg} / \mathrm{cm}^{2} \mathrm{MGF}$ electrodes represent the presence of graphitic carbon.

The results obtained from the Raman spectra suggest increased defects on the modified electrode based on the ratio obtained from $I_{\mathrm{D}} / I_{\mathrm{G}}$. The two distinct $\mathrm{D}$ band and $\mathrm{G}$ band peaks obtained at around 1350 and $1590 \mathrm{~cm}^{-1}$ respectively as shown in Fig. 8. The $I_{\mathrm{D}} / I_{\mathrm{G}}$ value of the $2 \mathrm{mg} / \mathrm{cm}^{2}$ MGF electrode was calculated to be 1.16 , whereas for UGF it is 1.06 , which indicates defects and increases in the structural disorder as a result of the modification of electrode by heterogeneous nitrogen-atom doped carbon $[25,36]$.

\section{Charge-discharge studies using $132 \mathrm{~cm}^{2}$ IRFB}

The charge-discharge studies were carried out at different current densities using the MGF electrode as the positive electrode and TTGF electrode as the negative electrode. The results obtained from the analysis are given in Table 2 . The $1 \mathrm{mg} / \mathrm{cm}^{2} \mathrm{MGF}$ electrode had resulted in the maximum current uptake of $30 \mathrm{~mA} / \mathrm{cm}^{2}$ and beyond which the cell was unable to charge. This can be attributed to the lack of electrochemically active catalysts over the electrode surface which increases the internal resistance of the electrode and hence decreases the electrochemical interaction of the electrode with the electrolyte. The cell constructed using a $3 \mathrm{mg} / \mathrm{cm}^{2}$ MGF electrode also resulted in the maximum current density of $30 \mathrm{~mA} / \mathrm{cm}^{2}$ after which the sudden charging and abrupt discharge were observed. This behavior can be ascribed to the saturation of NDCS concentration coated over the electrode surface which may result in the blockage of free space which is essential for the flow of electrolyte through the electrode surface. Based on the results of electrochemical measurements and the chargedischarge studies, the $2 \mathrm{mg} / \mathrm{cm}^{2}$ MGF electrode was considered as the positive electrode and the performance studies were carried out at different current densities (varied from $20 \mathrm{~mA} / \mathrm{cm}^{2}$ to $60 \mathrm{~mA} / \mathrm{cm}^{2}$ ). Fig. 9A represents the charge-discharge plots obtained from the 
performance studies. The modification of the electrode not only increased the efficiency of the battery but also increased the current up taking capacity. The IRFB employed the UGF electrode as the positive electrode was able to take a maximum current density of $20 \mathrm{~mA} / \mathrm{cm}^{2}$ and resulted in the $C E$ of $62 \%$.

It has been mentioned in the literature that, $V E$ is an important factor that determines the characteristics of the battery. The $V E$ can be increased by improving the electrocatalytic activity of the electrode and a better catalytic activity reduces the ohmic drop of the battery by providing enough electron conduction [31]. The efficiencies obtained for the IRFBs at different current densities have shown in Fig. 9B. The data obtained from the study reveals that the maximum voltaic efficiency can be achieved at lower current densities. This can be ascribed to the slow and study charging of the battery. At a higher current density of charging the battery has shown a high voltage drop (the arrow mark in Fig. 9A indicates the increase in the discharging voltage of the battery at different current density), this can be attributed to the false charging of the battery, as a result, the value of $C E$ and $V E$ will decrease. This affects the performance of the battery, especially on the $V E$ [31]. The cell was able to attain maximum $C E, V E$, and $E E$ values of $98 \%, 77 \%$, and $76 \%$ respectively at the current density of $30 \mathrm{~mA} / \mathrm{cm}^{2}$. The discharge was started from $1.16 \mathrm{~V}$ at $30 \mathrm{~mA} / \mathrm{cm}^{2}$ and $0.99 \mathrm{~V}$ for 50 $\mathrm{mA} / \mathrm{cm}^{2}$. The increase in the efficiencies of the IRFBs can be ascribed to the presence of electrochemically active nitrogen and oxygen functional groups over the electrode surface. During charge-discharge cycling, the electrolyte was observed to lose its stability after the $5^{\text {th }}$ cycle [33]. This may be resulted due to the deposition of the active material of the electrolyte over the electrode or membrane surface. The experiment was continued by taking fresh electrolyte after every fifth cycle, the data obtained from the study resulted in the electrode was stable enough with the repeatability of the efficiency values up to 15 cycles. The chargedischarge cycling carried out at $30 \mathrm{~mA} / \mathrm{cm}^{2}$ charging has shown in Fig. 9C. The battery resulted in an average $C E, V E$, and $E E$ values of $93 \%, 72 \%$, and $68 \%$ respectively for 15 cycles. From the results of $C E, V E$, and $E E$, it is concluded that the $2 \mathrm{mg} / \mathrm{cm}^{2} \mathrm{MGF}$ electrode has excellent stability and favors the kinetic reversibility for $\mathrm{Fe}^{3+} / \mathrm{Fe}^{2+}$ reaction. Thus the present study concludes that the modified graphite felt electrode using NDCS will be a potential candidate to be used as the positive electrode in the IRFBs. 


\section{Conclusion}

The IRFBs are considered as the futuristic way of energy storage devices, with environmental-friendly and cost-effective electrolyte. Synthesis of NDCS using dextrose as a precursor is a simple and economical way of synthesizing 3D carbon spheres. The EDAX analysis revealed the presence of nitrogen functional groups in the MGF electrode which increases the electrochemical character of the battery by increasing the electron conduction. The Raman study confirmed the increment of defective sites over the electrode surface which increases the surface area of the electrode. The results of electrochemical measurements shown $2 \mathrm{mg} / \mathrm{cm}^{2}$ MGF electrode give better kinetic reversibility and exhibits lower resistance towards electrode-electrolyte interaction. The charge-discharge studies for the IRFB fabricated using $2 \mathrm{mg} / \mathrm{cm}^{2}$ MGF electrode resulted in an excellent improvement in the $C E$, $V E$, and $E E$ values as $98 \%, 77 \%$, and $76 \%$ respectively. The increased $V E$ and $E E$ can be attributed to the charge storing capacity of the electrode by means of deposition of electrochemically active NDCS catalysts. Thus, the improved performance of the flow cell graphite electrode modified with carbon doped with nitrogen functional groups can be a novel, potential electrode to be used as a positive electrode for IRFBs. 


\section{Acknowledgments}

We gratefully thank the Department of Science and Technology (DST), India, for financial support under the MES scheme. We also thank the Centre for Incubation, Innovation, Research and Consultancy (CIIRC), Jyothy Institute of Technology, and Sri Sringeri Sharadha PEEtam for supporting this research. 


\section{References}

1. T. Luo, O. David, Y. Gendel and M. Wessling, J. Power Sources 312, $45-54$ (2016)

2. Z. Xie, Q. Liu, Z. Chang and X. Zhang, Electrochim. Acta 90, 695-704 (2013)

3. W. Wang, Q. Luo, B. Li, X. Wei, L. Li and Z. Yang, Advan. Func. Mater. 23, 970-986 (2013)

4. W. Wang, Q. Luo, Z. Nie, M. Vijayakumar, X. Wei, B. Li, F. Chen, B. Chen, Y. Shao and G.-G. $\mathrm{Xia}$, Recent Progress in Redox Flow Battery Research and Development at Pacific Northwest National Lab (2012)

5. L. Joerissen, J. Garche, C. Fabjan and G. Tomazic, J. Power source 127, 98-104 (2004)

6. P. Alotto, M. Guarnieri and F. Moro, Renew. Sust. Energ. Rev. 29, 325-335 (2014)

7. A. Dinesh, S. Olivera, K. Venkatesh, M. S. Santosh, M. G. Priya, A. M. Asiri and H. B. Muralidhara, Environ. Chem. Lett. 1-12 (2018)

8. C. P. De Leon, A. Frías-Ferrer, J. González-García, D. Szánto and F. C. Walsh, J Power Sources 160, 716-732 (2006)

9. M. H. Chakrabarti, S. Hajimolana, F. S. Mjalli, M. Saleem and I. Mustafa, Arab. J. Sci. Eng. 38, 723-739 (2013)

10.A. Z. Weber, M. M. Mench, J. P. Meyers, P. N. Ross, J. T. Gostick and Q. Liu, J. Appl. Electrochem. 41, 1137 (2011)

11.U. T. Austin, A. Z. Weber, M. M. Mench, J. P. Meyers, P. N. Ross, J. T. Gostick and Q. Liu, J. of Appl. Electrochem. 41 (2011)

12.M. Skyllas-Kazacos, M. Chakrabarti, S. Hajimolana, F. Mjalli and M. Saleem, J. Electrochem. Soc. 158, R55-R79 (2011)

13.L. Hruska and R. Savinell, J. Electrochem. Soc. 128, 18-25 (1981)

14.M. C. Tucker, A. Phillips and A. Z. Weber, ChemSusChem 8, 3996-4004 (2015)

15.K. L. Hawthorne, J. S. Wainright and R. F. Savinell, J. Electrochem. Soc. 161, A1662-A16712014

16.K. L. Hawthorne, Case Western Reserve University (2014)

17.M. Park, J. Ryu, Y. Kim and J. Cho, Energy. Environ. Sci. 7, 3727-3735 (2014)

18.D. Anarghya, M. Anantha, K. Venkatesh, M. Santosh, M. G. Priya and H. Muralidhara, J. Electroanal. Chem. 114577 (2020)

19.M. Anantha, D. Anarghya, C. Hu, N. Reddy, K. Venkatesh and H. Muralidhara, J. Mater. Sci: Mater. Electron. 1-10 (2020)

20.H. Zhang, M. Hu, Q. Lv, L. Yang and R. Lv, Electrochim. Acta 297, 365-371 (2019)

21.H. X. Xiang, A. D. Tan, J. H. Piao, Z. Y. Fu and Z. X. Liang, Small 15, 1901848 (2019)

22.C. Li, Y. Wang, N. Xiao, H. Li, Y. Ji, Z. Guo, C. Liu and J. Qiu, C 151, 46-52 (2019)

23.Q. Yu, J. Lv, Z. Liu, M. Xu, W. Yang, K. A. Owusu, L. Mai, D. Zhao and L. Zhou, Science Bulletin, 64, 1617-1624 (2019)

24.Y. Shao, J. Sui, G. Yin and Y. Gao, Applied Catalysis B: Environmental 79, 89-99 (2008)

25.Z. He, Y. Jiang, Y. Wei, C. Zhao, F. Jiang, L. Li, H. Zhou, W. Meng, L. Wang and L. Dai, Electrochim. Acta 259, 122-130 (2018)

26.H. Lee and H. Kim, J. Appl. Electrochem. 43, 553-557 (2013)

27.M. Li, W. Li and S. Liu, Carbohydr. Res. 346, 999-1004 (2011)

28. Y. Mi, W. Hu, Y. Dan and Y. Liu, Mater. Lett. 62, 1194-1196 (2008)

29.J. Liu, P. Tian, J. Ye, L. Zhou, W. Gong, Y. Lin and G. Ning, Chem. Lett. 38, 948-949 (2009)

30.S. Olivera, K. Venkatesh, N. Reddy, B. K. Jayanna, A. M. Asiri, S. Rtimi and H. B. Muralidhara, Environ. Technol. Innov. 12, 160-171 (2018)

31.S. Suresh, M. Ulaganathan, R. Aswathy and P. Ragupathy, ChemElectroChem 5, 3411-3418 (2018)

32.K. L. Hawthorne, T. J. Petek, M. A. Miller, J. S. Wainright and R. F. Savinell, J. Electrochem. Soc. 162, A108-A113 (2015)

33. Y. Zhen, C. Zhang, J. Yuan, Y. Zhao and Y. Li, J. Power Sources 445, 227331 (2020)

34.B. Sun and M. Skyllas-Kazacos, Electrochim. Acta 37, 1253-1260 (1992)

35. Y. Shao, X. Wang, M. Engelhard, C. Wang, S. Dai, J. Liu, Z. Yang and Y. Lin, J Power Sources 195, 4375-4379 (2010)

36. Z. He, M. Li, Y. Li, L. Wang, J. Zhu, W. Meng, C. Li, H. Zhou and L. Dai, Appl. Surf. Sci. 469, 423-43 (2019) 


\section{Figure captions}

Fig. 1 Graphical representation of IRFBs

Fig. 2 The three-electrode cell assembly used in the electrochemical measurement studies

Fig. $3 \mathrm{CV}$ curves for A UGF and MGF electrodes B $2 \mathrm{mg} / \mathrm{cm}^{2}$ electrode at different scan rates

Fig. 4 Potentiodynamic polarization studies for UGF, TTGF, and MGF electrodes

Fig. 5 SEM images for A NDCS, B UGF, C TTG, D $1 \mathrm{mg} / \mathrm{cm}^{2} \mathrm{MGF}$ E $2 \mathrm{mg} / \mathrm{cm}^{2} \mathrm{MGF}$, and F $3 \mathrm{mg} / \mathrm{cm}^{2}$ MGF electrode

Fig. 6 EDAX spectrum for NDCS and $2 \mathrm{mg} / \mathrm{cm}^{2}$ MGF electrode

Fig. 7 XRD studies for NDCS, UGF and $2 \mathrm{mg} / \mathrm{cm}^{2}$ MGF electrode

Fig. 8 Raman spectrum for UGF and $2 \mathrm{mg} / \mathrm{cm}^{2} \mathrm{MGF}$ electrode

Fig. 9 A Charge-discharge curves for $2 \mathrm{mg} / \mathrm{cm}^{2} \mathrm{MGF}$ electrode at different current densities B Efficiencies of the UGF electrode at current density of $20 \mathrm{~mA} / \mathrm{cm}^{2}-10 \mathrm{~mA} / \mathrm{cm}^{2}$ and $2 \mathrm{mg} / \mathrm{cm}^{2}$ MGF electrode at different current densities, and $\mathbf{C}$ Charge-discharge cycling for $2 \mathrm{mg} / \mathrm{cm}^{2}$ MGF electrode at a current density of $30 \mathrm{mAcm}{ }^{2}-15 \mathrm{~mA} / \mathrm{cm}^{2}$ 


\section{Declaration of interests}

$\bigotimes$ The authors declare that they have no known competing financial interests or personal relationships that could have appeared to influence the work reported in this paper.

$\square$ The authors declare the following financial interests/personal relationships which may be considered as potential competing interests: 
Figures

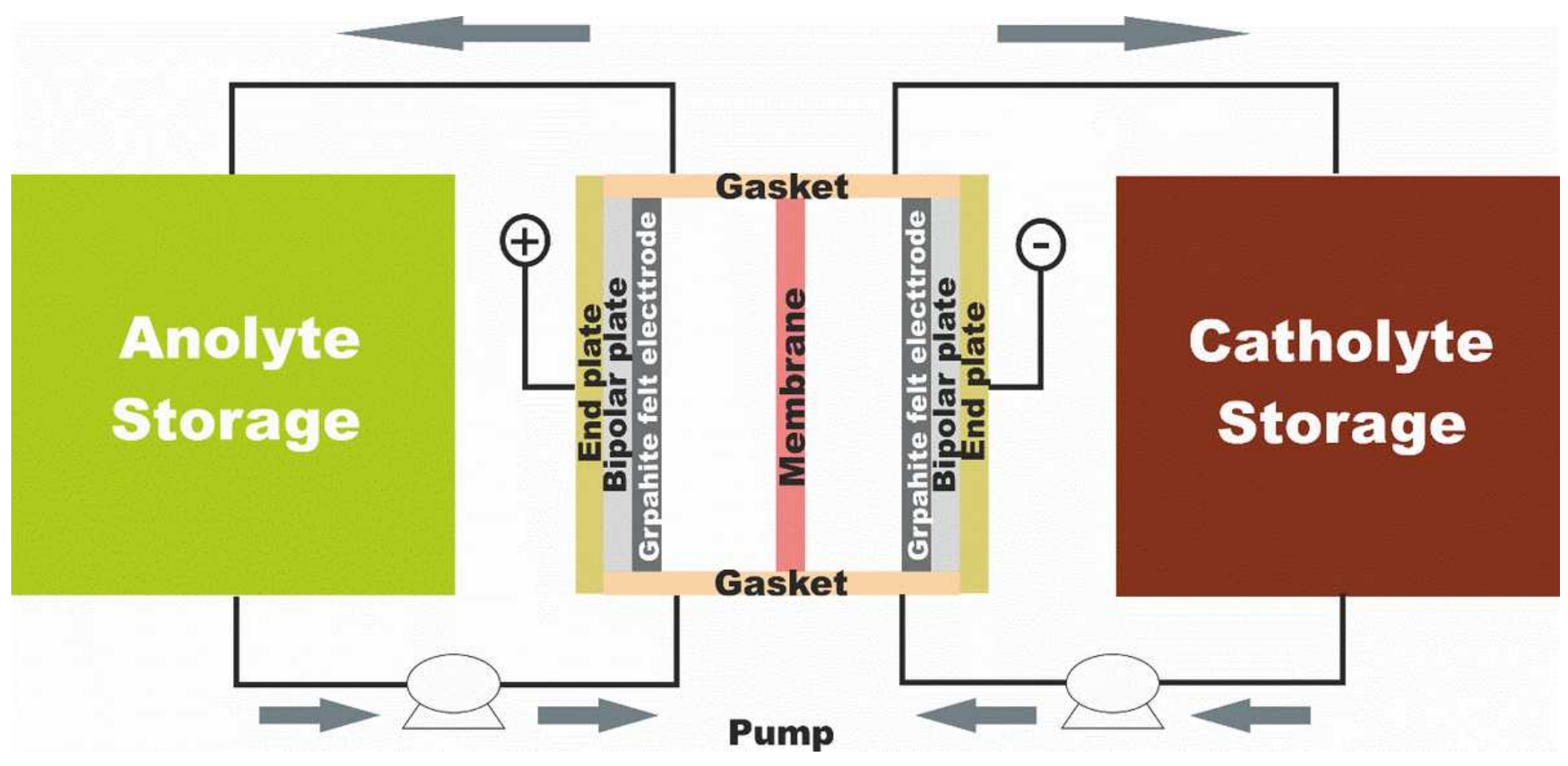

Figure 1

Graphical representation of IRFBs 


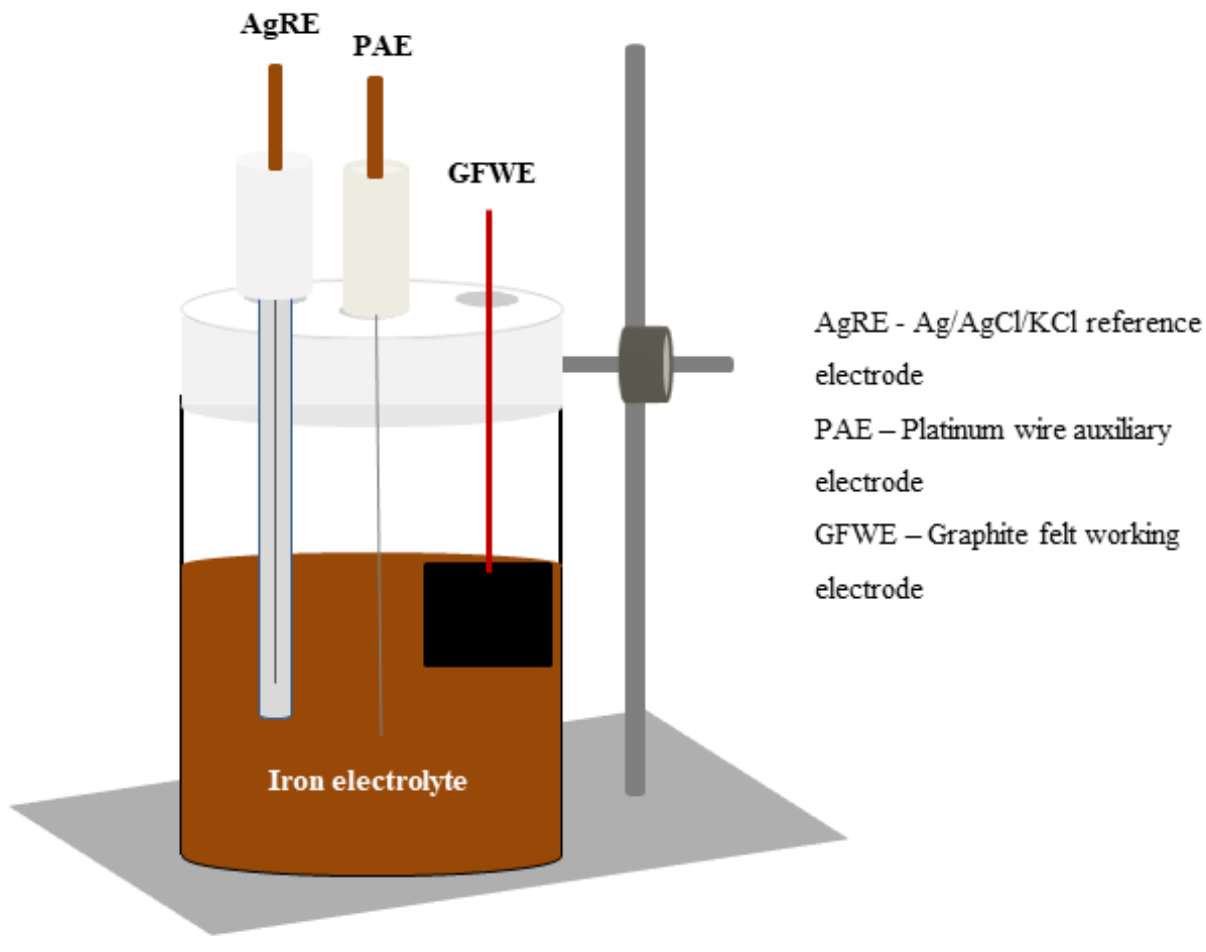

Figure 2

The three-electrode cell assembly used in the electrochemical measurement studies
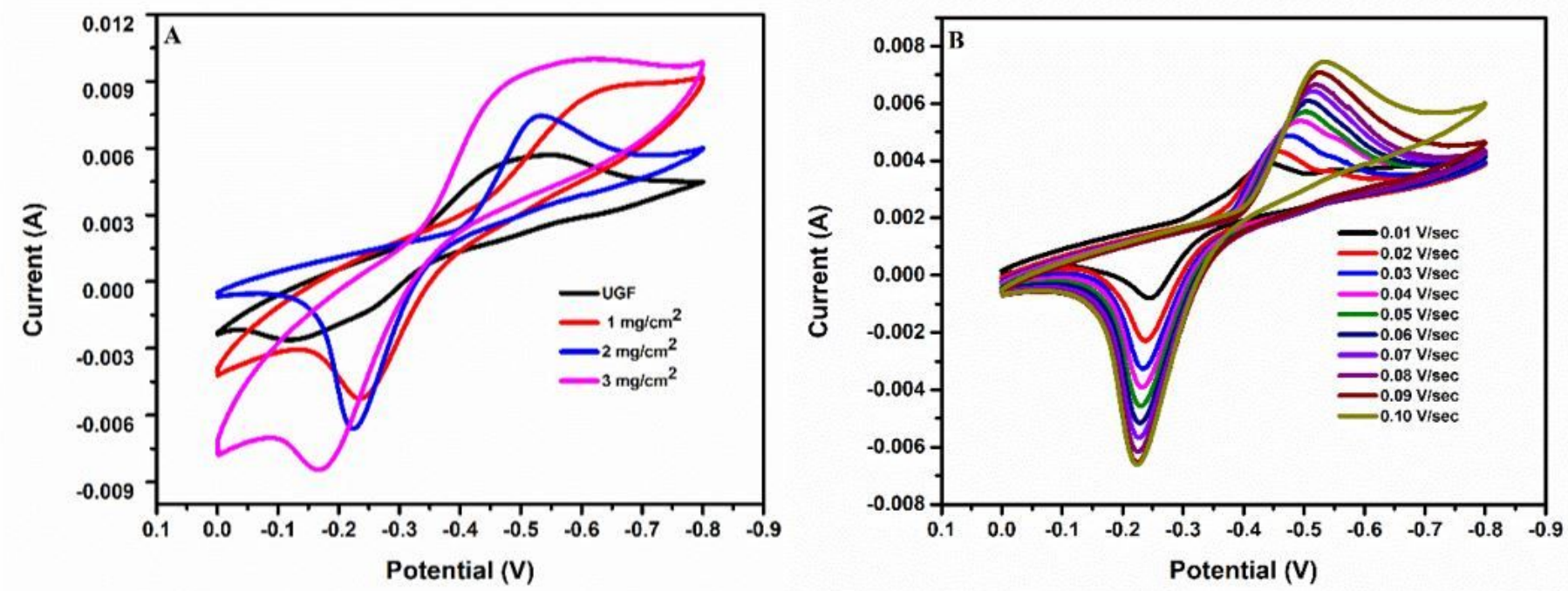
Figure 3

CV curves for A UGF and MGF electrodes B $2 \mathrm{mg} / \mathrm{cm} 2$ electrode at different scan rates

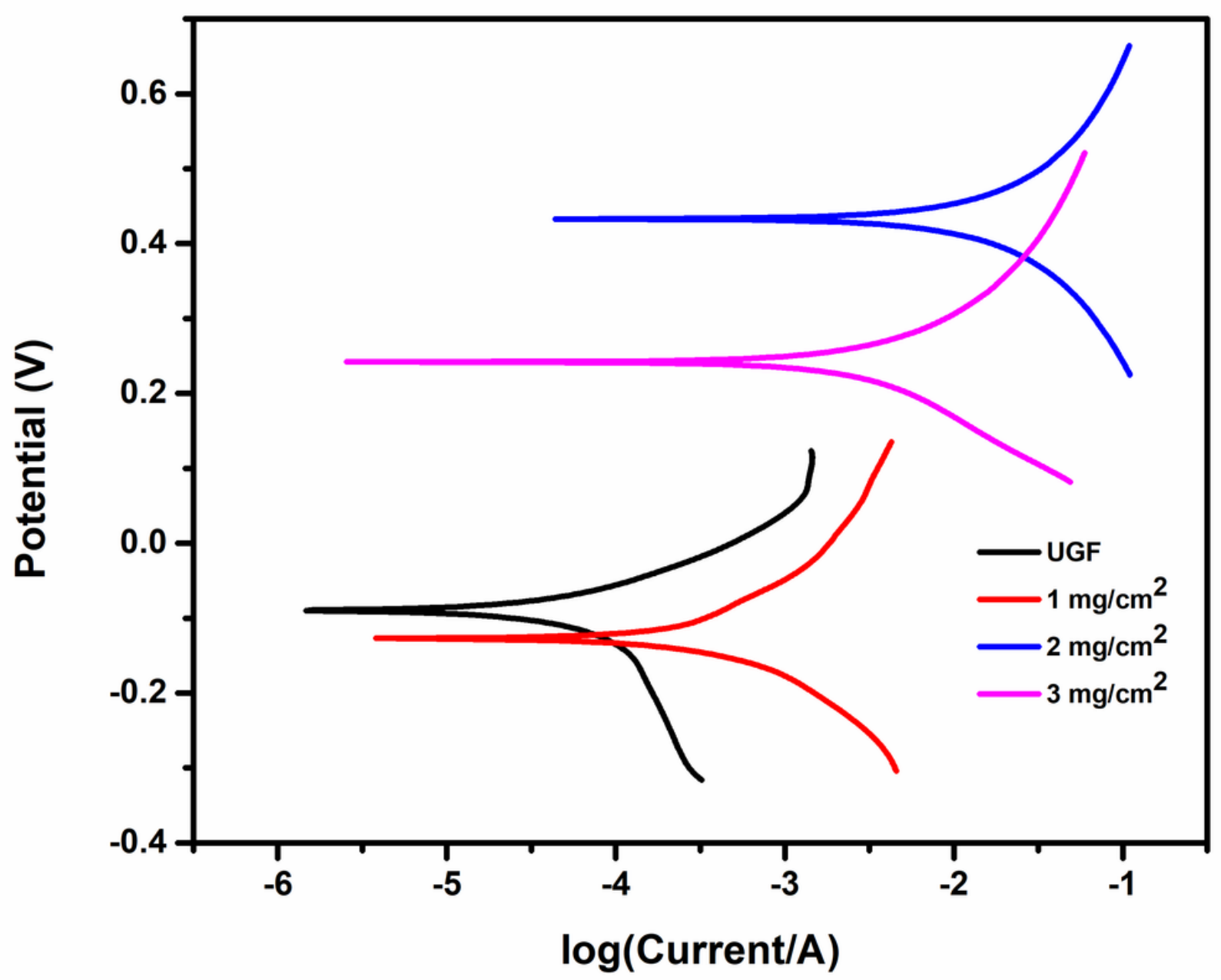

Figure 4

Potentiodynamic polarization studies for UGF, TTGF, and MGF electrodes 


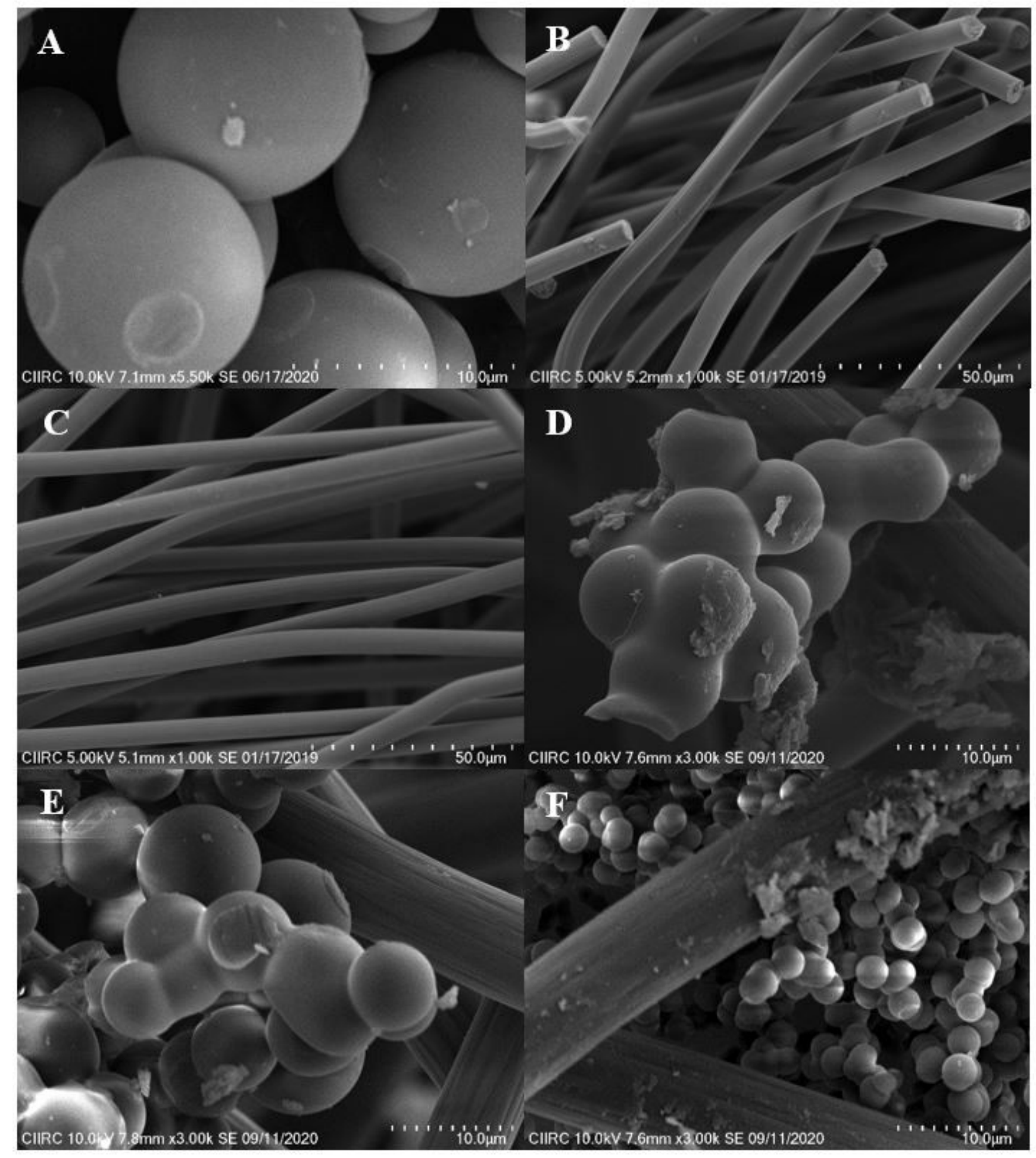

Figure 5

SEM images for A NDCS, B UGF, C TTG, D $1 \mathrm{mg} / \mathrm{cm} 2 \mathrm{MGF} E 2 \mathrm{mg} / \mathrm{cm} 2 \mathrm{MGF}$, and F $3 \mathrm{mg} / \mathrm{cm} 2 \mathrm{MGF}$ electrode 


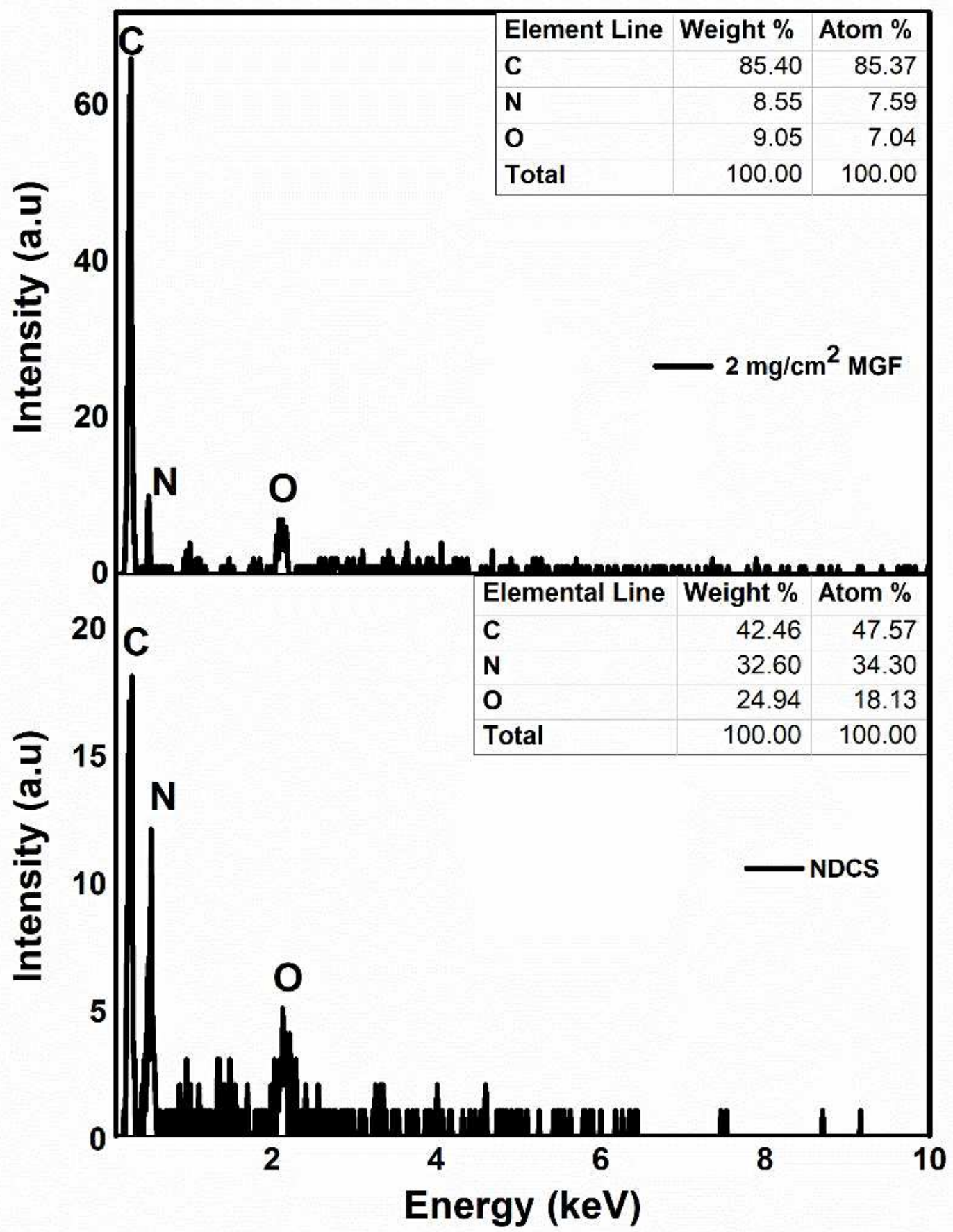

Figure 6

EDAX spectrum for NDCS and $2 \mathrm{mg} / \mathrm{cm} 2$ MGF electrode 


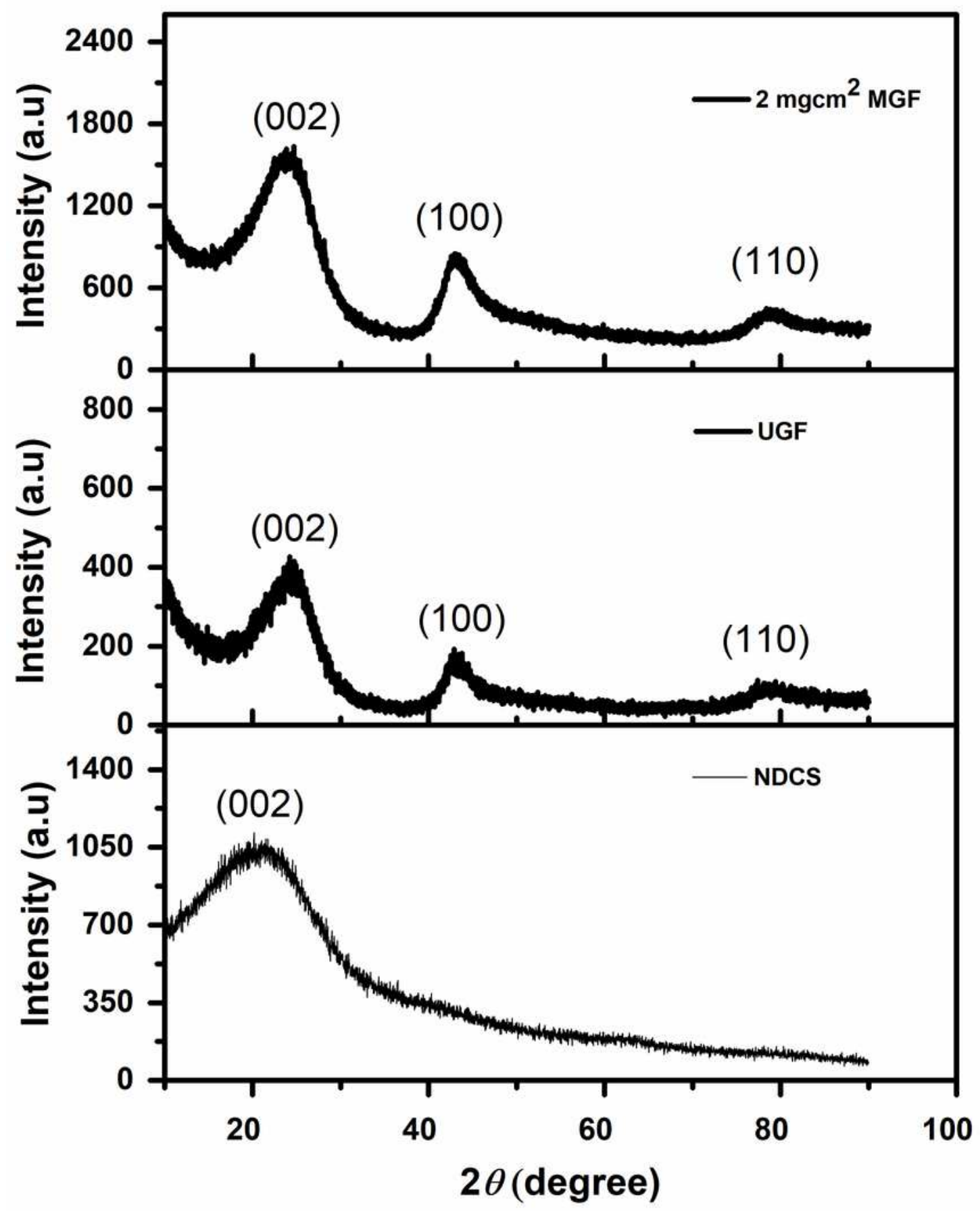

Figure 7

XRD studies for NDCS, UGF and $2 \mathrm{mg} / \mathrm{cm} 2$ MGF electrode 


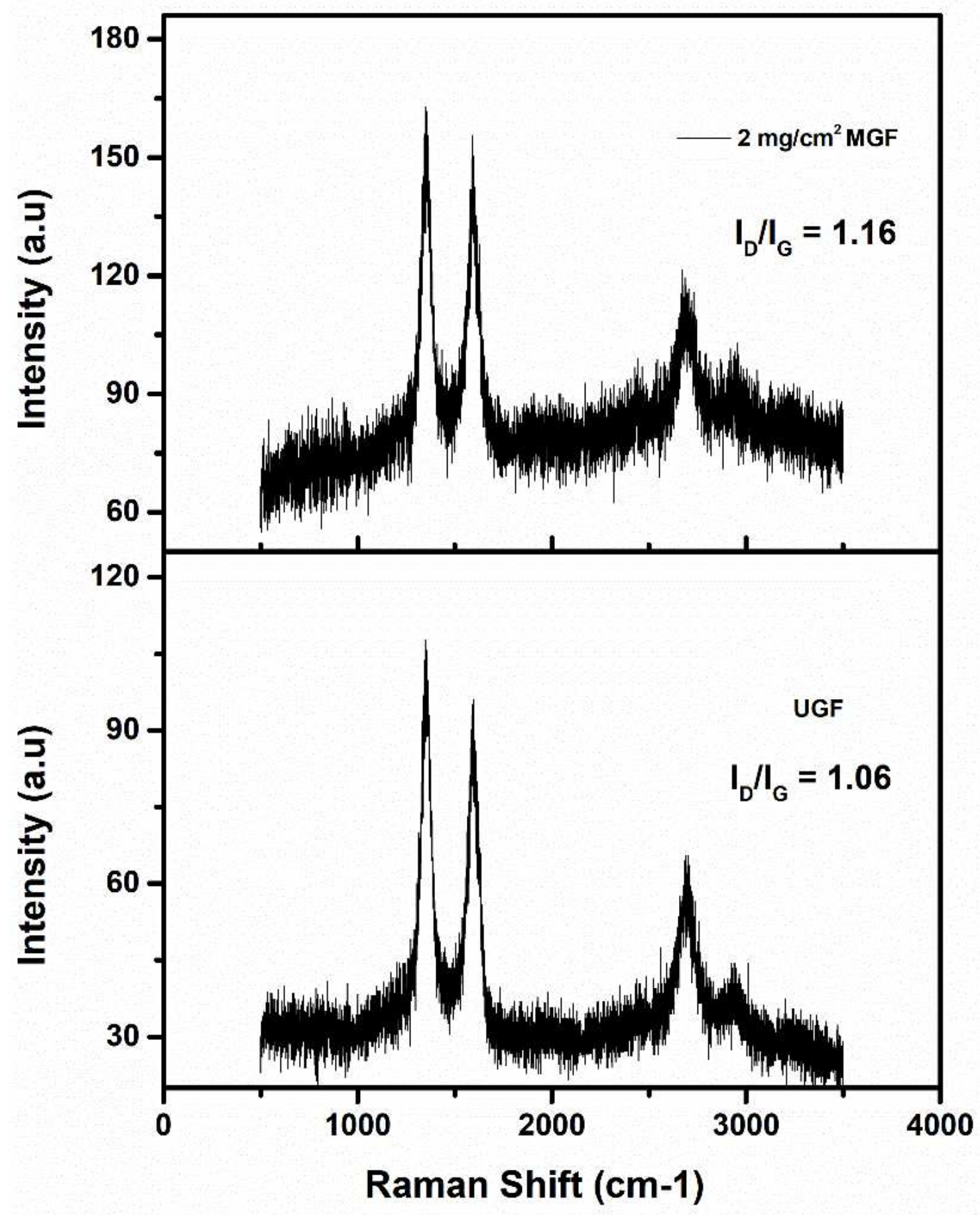

Figure 8

Raman spectrum for UGF and $2 \mathrm{mg} / \mathrm{cm} 2$ MGF electrode 

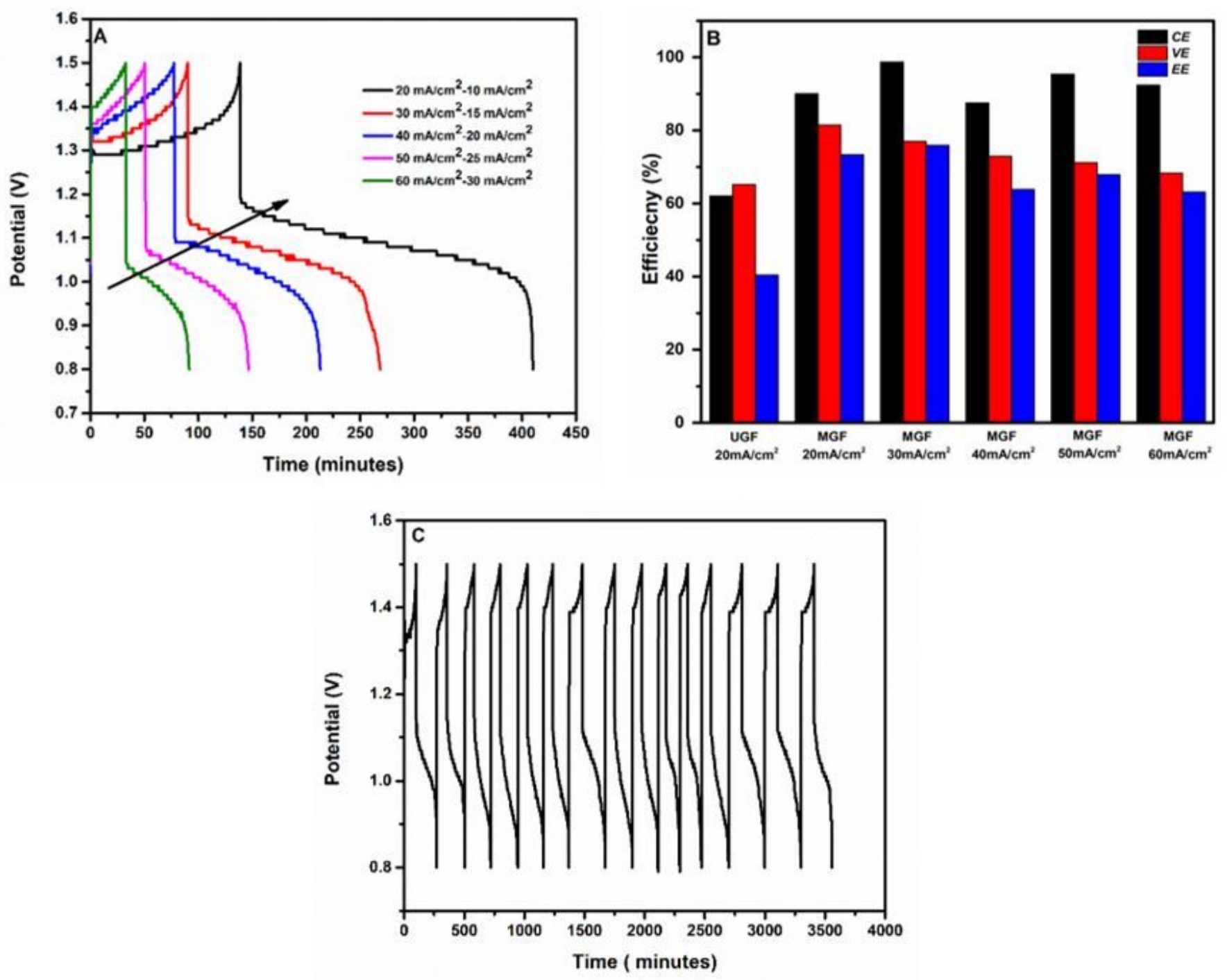

Figure 9

A Charge-discharge curves for $2 \mathrm{mg} / \mathrm{cm} 2 \mathrm{MGF}$ electrode at different current densities B Efficiencies of the UGF electrode at current density of $20 \mathrm{~mA} / \mathrm{cm} 2-10 \mathrm{~mA} / \mathrm{cm} 2$ and $2 \mathrm{mg} / \mathrm{cm} 2 \mathrm{MGF}$ electrode at different current densities, and C Charge-discharge cycling for $2 \mathrm{mg} / \mathrm{cm} 2 \mathrm{MGF}$ electrode at a current density of 30 $\mathrm{mAcm} 2-15 \mathrm{~mA} / \mathrm{cm} 2$ 